\title{
Effect of a change in global metabolic rate on peripheral oxygen consumption in neonates
}

\author{
I A-A Hassan, Y A Wickramasinghe, S A Spencer
}

Arch Dis Child Fetal Neonatal Ed 2003;88:F143-F146

See end of article for authors' affiliations ....................

Correspondence to: Dr Spencer, Neonatal Unit, Maternity Building, North Staffordshire Hospital (City General), Newcastle Road, Stoke on Trent ST4 6QG, UK; andy.spencer@ nstaffsh.wmids.nhs.uk

Accepted 16 July 2002

\begin{abstract}
Aim: To evaluate the effect of an induced change in global metabolic rate on peripheral oxygen consumption $\left(\mathrm{VO}_{2}\right)$ in healthy full term neonates.

Subjects and methods: Twenty four healthy full term neonates were studied. Peripheral $\mathrm{VO}_{2}$ was measured by near infrared spectroscopy (NIRS) using arterial occlusion and measurement of the oxyhaemoglobin $\left(\mathrm{HbO}_{2}\right)$ decrement slope. Global $\mathrm{VO}_{2}$ was measured by open circuit calorimetry. Global and peripheral $\mathrm{VO}_{2}$ were measured in each neonate before and after a routine bath. Abdominal and forearm skin temperatures were also recorded.

Results: Nineteen neonates completed the study. Global $\mathrm{Vo}_{2}$ increased by $30.7 \%(p=0.001)$, and peripheral $\mathrm{VO}_{2}$ by $23.1 \%(\mathrm{p}=0.001)$. A correlation between the fractional changes in global and peripheral $\mathrm{VO}_{2}$ was apparent $(r=0.76, \mathrm{p}=0.001)$. Abdominal skin temperature decreased by $0.8^{\circ} \mathrm{C}$ $(p=0.001)$, and forearm skin temperature by $0.6^{\circ} \mathrm{C}(p=0.04)$.

Conclusions: Measurement of peripheral $\mathrm{VO}_{2}$ using NIRS with arterial occlusion is responsive to conditions that increase global metabolic rate. Any change in global $\mathrm{VO}_{2}$ must be taken into consideration during the interpretation of peripheral $\mathrm{VO}_{2}$ measurements in neonates.
\end{abstract}

E arly in circulatory compromise, compensatory mechanisms maintain oxygen delivery to vital organs, such as the brain and heart, through redistribution of blood flow away from the periphery. This will give rise to reduced peripheral perfusion, thereby limiting oxygen uptake by these areas. Studies during critical care in adults, using invasive oxygen electrodes, suggest that hypoxic changes in skeletal muscle may be observed before there is a significant change in blood pressure. ${ }^{1}$ Therefore a method for assessment of peripheral oxygen consumption in neonates may give an early warning of the need for circulatory support during critical care. ${ }^{2}$ Cerebral ischaemic lesions are still an important cause of neurodevelopmental problems in preterm infants. ${ }^{3}$ There is evidence that prevention of hypotension is important in the prevention of these lesions, ${ }^{4-6}$ and the British Association of Perinatal Medicine guidelines ${ }^{7}$ promote the maintenance of mean arterial pressure above predefined limits. Unfortunately this strategy has not been effective in preventing the development of these lesions. The cause of this white matter damage is almost certainly multifactorial, with contributions from antenatal infection (chorioamnionitis) ${ }^{89}$ and hypocapnia. ${ }^{10}{ }^{11}$ Nevertheless it is possible that improved management of the circulation, particularly in the first 48 hours of life may improve brain perfusion and lead to improved outcomes for these babies.

Previously we reported a non-invasive method for measurement of peripheral oxygen consumption $\left(\mathrm{VO}_{2}\right)$ in neonates using near infrared spectroscopy (NIRS) with arterial occlusion. ${ }^{12}$ Before assessing this technique during critical care, it was necessary to understand how changes in the external environment may affect the measurements obtained. Changes in environmental temperature may have a profound effect on both metabolic rate $\mathrm{r}^{13}$ and limb temperature. Consequently studies were undertaken in healthy term infants to examine the effects of interventions that were designed to mainly affect either limb temperature (limb cooling) or global metabolic rate. This paper describes the results of the second of these two interventions.

A non-invasive intervention that would act principally to increase global metabolic rate was required. The routine postnatal bath was chosen because it is a powerful stimulus of metabolic rate ${ }^{14}$ and is undertaken as a normal part of care. Although peripheral temperature may change as a consequence of the bath, ${ }^{15}$ it was thought that the effect on global metabolic rate would be much more significant than in the limb cooling studies.

\section{AIM}

The aim of the study was to evaluate the effect of an alteration in global metabolic rate on peripheral oxygen consumption $\left(\mathrm{VO}_{2}\right)$ in healthy full term neonates.

\section{METHODS}

\section{Subjects}

Healthy term infants in the first few days of life were recruited on the postnatal wards of North Staffordshire Hospital. None were receiving medication or supplemental oxygen.

\section{Consent}

The study and the information leaflet given to parents were approved by North Staffordshire research ethics committee. Parental written informed consent was obtained before the study.

\begin{abstract}
Measurements
Peripheral $\mathrm{VO}_{2}$

Peripheral $\mathrm{VO}_{2}$ was measured using NIRS and arterial occlusion as previously described. ${ }^{12}$ In brief, NIRS can be used to monitor changes in concentrations of oxygenated haemoglobin $\left(\mathrm{HbO}_{2}\right)$ and total haemoglobin $(\mathrm{HbT})$. When arterial occlusion is performed, there is an abrupt decrease in $\mathrm{HbO}_{2}$, which is entirely due to oxygen utilisation, provided that no blood enters or leaves the limb. Thus peripheral $\mathrm{VO}_{2}$ can be calculated by measurement of the $\mathrm{HbO}_{2}$ decrement slope provided that HbT does not change ( fig 1). Not every occlusion
\end{abstract}

Abbreviations: $\mathrm{VO}_{2}$, oxygen consumption; NIRS, near infrared spectroscopy; $\mathrm{HbO}_{2}$, oxygenated haemoglobin; $\mathrm{HbT}$, total haemoglobin; $\mathrm{Cl}$, confidence intervals 


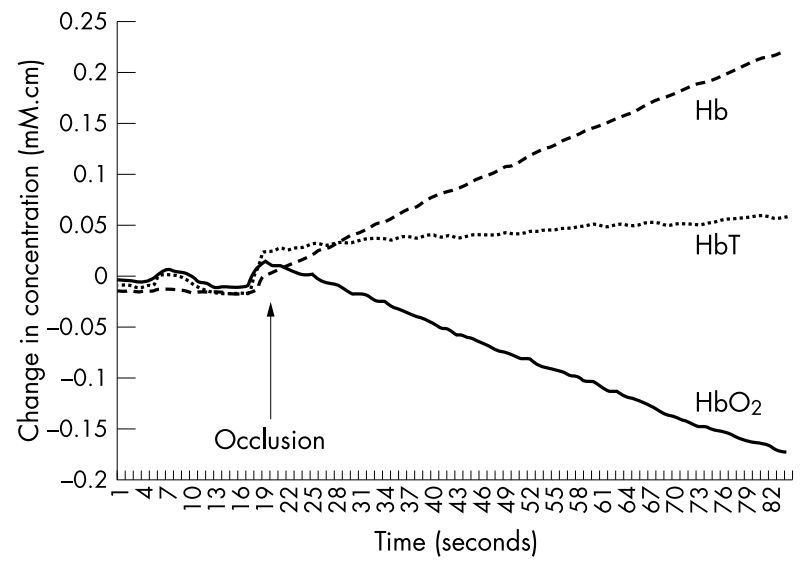

Figure 1 A typical trace showing the immediate rise in haemoglobin $(\mathrm{Hb})$ and fall in oxygenated haemoglobin $\left(\mathrm{HbO}_{2}\right)$ that occurs as a result of oxygen utilisation after arterial occlusion. In this case, there is a slow drift upwards of total haemoglobin ( $\mathrm{HbT})$, which must be less than $10 \%$ of the change in $\mathrm{HbO}_{2}$ for the occlusion to be valid.

is satisfactory, so in our previous work criteria were defined for accepting an occlusion as suitable for further analysis. Only occlusions meeting these predefined criteria $^{12}$ have been included in the results. In order for an occlusion to pass, there has to be an abrupt decrease in $\mathrm{HbO}_{2}$ and increase in $\mathrm{Hb}$ immediately after the occlusion. The HbT trace has to remain stable with a maximum permitted change of $<10 \%$ of the change in $\mathrm{HbO}_{2}$. The coefficient of variation for the measurement of $\mathrm{VO}_{2}$ is $6.6 \%$.

\section{NIRS units}

The basic uncorrected units for $\mathrm{HbO}_{2}$ is $\mathrm{mM} . \mathrm{cm}$. $\mathrm{VO}_{2}$ is calculated using the rate of change in the $\mathrm{HbO}_{2}$ signal during arterial occlusion and is expressed as $\mathrm{mM} \mathrm{HbO}_{2} \cdot \mathrm{cm} / \mathrm{min}$. By taking into account the molecular ratio of $\mathrm{Hb}$ to $\mathrm{O}_{2}$, which is $1: 4, \mathrm{VO}_{2}$ can be expressed as $\mathrm{mM} \mathrm{O}_{2} \cdot \mathrm{cm} / \mathrm{min}$. These units have been used because no assumptions about differential path length factor are required. Thus comparisons between babies are valid. Other studies have used $\mu \mathrm{mol} \mathrm{O}_{2} / 100 \mathrm{ml} / \mathrm{min}^{2}$ which requires a path length correction factor which is assumed to be a constant of 3.59. For a distance of $3 \mathrm{~cm}$ between probes, the conversion factor is $100 /(3.59 \times 3)$, which is 9.3 . Thus $\mu \mathrm{mol}$ $\mathrm{O}_{2} / 100 \mathrm{ml} / \mathrm{min}=9.3 \times \mathrm{mM} \mathrm{O}_{2} \cdot \mathrm{cm} / \mathrm{min}$.

\section{Global $\mathrm{VO}_{2}$}

This was measured using open circuit calorimetry (Morgan Ltd, Gillingham, Kent, UK). ${ }^{16}$ The technique was modified to use a facemask rather than an incubator for gas collection. ${ }^{17}$

Briefly, the infant's expired air was continuously drawn through a face mask (cushion flex infant mask; Intersurgical Company, Wokingham, Berkshire, UK) held in front of the infant's nose and mouth at a constant flow rate of 2-3 litres/min.

Room air was also continuously sampled, and the oxygen concentration of both the mixed expired air and room air was measured continuously by open circuit calorimetry.

Global $\mathrm{VO}_{2}$ was calculated using the formula:

$$
\mathrm{VO}_{2}=\mathrm{Q}\left(\mathrm{FIO}_{2}-\mathrm{FEO}_{2}\right)
$$

where $\mathrm{Q}=$ flow through the system, $\mathrm{FIO}_{2}=$ fractional concentration of oxygen in inspired air (room air), and $\mathrm{FEO}_{2}=$ fractional concentration of oxygen in expired air (infant's expired air). Global $\mathrm{VO}_{2}$ results were expressed as $\mathrm{ml}$ $\mathrm{O}_{2} / \mathrm{kg} / \mathrm{min}$.

Table 1 Details of neonates that completed the study

Number completing study

Gestational age (weeks)

Mode of delivery

Birth weight $(\mathrm{kg})$

Postnatal age (days)

F:M

Values are either mean (SD) or median (range). CS, Caesarean

section; VD, vaginal delivery; $M$, male; $F$, female.

\section{Skin temperature}

Forearm and abdominal skin temperatures were measured with a digital thermometer (Libra Medical), which had previously been calibrated against a mercury in glass thermometer. The skin probe was placed on the dorsal aspect of the forearm opposite the NIRS optode holders. A second temperature probe placed on the upper abdomen continuously measured abdominal skin temperature.

\section{Protocol}

No change in the postnatal bath routine was required for the purpose of this study apart from standardising the time in relation to feeds. The same researcher performed measurements on all the neonates at the same time of day ( $9 \mathrm{am})$, 1-1.5 hours after a feed. Shortly before the bath was due the neonate was placed fully clothed in his/her cot. One arm was then uncovered and an appropriate sized neonatal cuff was placed around the upper arm. NIRS optodes were placed on the anterior surface of the forearm, and a skin temperature probe attached as previously described. The distance between the transmitting and receiving optical probes was $3 \mathrm{~cm}$. The arm was then covered. A second temperature probe was placed on the anterior abdominal wall.

Once the baby was settled, initial measurements were taken. Global $\mathrm{Vo}_{2}$, forearm $\mathrm{VO}_{2}$ (up to three times), and forearm and abdominal skin temperature were all recorded. The blood pressure cuff was removed, and the NIRS optodes and skin temperature probes were disconnected before the mother or a nurse bathed the baby. After the bath, the baby was dried and fully dressed apart from the arm, which was dried but left exposed to facilitate rapid attachment of the cuff, NIRS optodes, and skin temperature probes. Once this equipment was in place, the arm was covered to prevent further cooling. Within two or three minutes of the end of the bath, a full set of measurements were taken. The room temperature and duration of the bath were also recorded.

\section{Data analysis}

Results are presented as means with 95\% confidence intervals ( $95 \% \mathrm{CI}$ ). A paired $t$ test (before and after) was used to determine the effect of the bath on skin temperatures and global and peripheral $\mathrm{VO}_{2}$. Where more than one successful measurement of peripheral $\mathrm{VO}_{2}$ was obtained in a subject, before or after the intervention, then the mean value was used. The level of significance was set at 0.05 .

\section{RESULTS}

\section{Subjects}

Twenty four neonates were included in this study. Five failed to complete the whole study and were therefore excluded from the analysis. Three babies could not be studied after their bath because of unsettled behaviour, excessive movements, or the need for a feed. In a fourth case, consent was withdrawn after the bath, and one baby was withdrawn because of equipment failure. Table 1 gives details of the 19 neonates that completed the study.

Temperature and $\mathrm{VO}_{2}$ results

The mean (SD) room temperature was $28.4(1.5)^{\circ} \mathrm{C}$. The bath lasted 10-15 minutes. 
Table 2 Peripheral and global oxygen consumption $\mathrm{VO}_{2}$ before and after a bath

\begin{tabular}{|c|c|c|c|c|c|}
\hline & Before & After & Difference & $\begin{array}{l}\text { Change } \\
(\%)\end{array}$ & $\mathrm{p}$ Value \\
\hline $\begin{array}{l}\text { Forearm skin temperature }\left({ }^{\circ} \mathrm{C}\right) \\
95 \% \mathrm{Cl}\end{array}$ & $\begin{array}{l}33.8 \\
33 \text { to } 34.6\end{array}$ & $\begin{array}{l}33.2 \\
32.4 \text { to } 34\end{array}$ & $\begin{array}{l}-0.6 \\
-1.31 \text { to }-0.039\end{array}$ & -1.8 & 0.001 \\
\hline $\begin{array}{l}\text { Abdominal skin temperature }\left({ }^{\circ} \mathrm{C}\right) \\
95 \% \mathrm{Cl}\end{array}$ & $\begin{array}{l}37 \\
36.8 \text { to } 37.2\end{array}$ & $\begin{array}{l}36.2 \\
35.8 \text { to } 36.6\end{array}$ & $\begin{array}{l}-0.8 \\
-1.23 \text { to }-0.37\end{array}$ & -2.2 & 0.05 \\
\hline $\begin{array}{l}\text { Peripheral } \mathrm{VO}_{2}\left(\mathrm{mM} \mathrm{O}_{2} \cdot \mathrm{cm} / \mathrm{min}\right) \\
95 \% \mathrm{Cl}\end{array}$ & $\begin{array}{l}1.47 \\
1.11 \text { to } 1.83\end{array}$ & $\begin{array}{l}1.81 \\
1.44 \text { to } 2.18\end{array}$ & $\begin{array}{l}+0.34 \\
0.207 \text { to } 0.405\end{array}$ & +23.1 & 0.001 \\
\hline $\begin{array}{l}\text { Global VO} \mathrm{O}_{2}(\mathrm{ml} / \mathrm{kg} / \mathrm{min}) \\
95 \% \mathrm{Cl}\end{array}$ & $\begin{array}{l}7.86 \\
6.78 \text { to } 8.94\end{array}$ & $\begin{array}{l}10.27 \\
8.63 \text { to } 11.9\end{array}$ & $\begin{array}{l}+2.41 \\
1.27 \text { to } 3.55\end{array}$ & +30.7 & 0.001 \\
\hline
\end{tabular}

Results are means with $95 \%$ confidence intervals $(\mathrm{Cl})$.

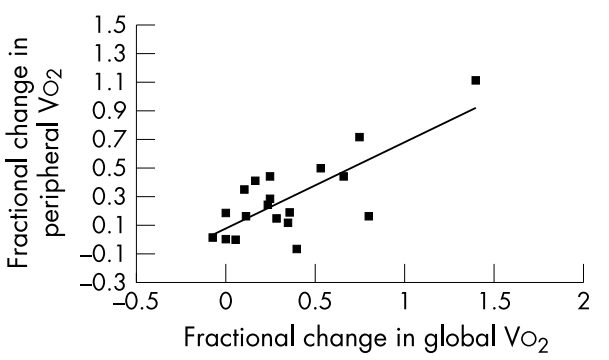

Figure 2 Correlation between change in peripheral and global oxygen consumption $\left(\mathrm{VO}_{2}\right)$ as a result of a bath (19 pairs). $r=0.76$ $(p<0.001)$.

Table 2 shows the results. Results of particular relevance are described below.

- There was a small but significant fall in both the mean abdominal skin temperature and the mean forearm skin temperature after the bath.

- There was a $30 \%$ increase in mean global $\mathrm{Vo}_{2}$ after the bath, which was highly significant.

- Mean forearm $\mathrm{VO}_{2}$ increased by $23 \%$, which was also highly significant.

A correlation between change in peripheral and global $\mathrm{VO}_{2}$ was apparent when they were plotted for individual babies ( fig 2).

\section{DISCUSSION}

As expected, ${ }^{14}$ after a cold stimulus, in this case a bath, there was a significant rise in metabolic rate. This was associated with a clear and significant rise in peripheral $\mathrm{VO}_{2}$. There was a correlation between change in global metabolic rate and change in peripheral metabolic rate.

Measurement of global $\mathrm{VO}_{2}$ is a well established technique which can be performed with an error of $<5 \%$ with the equipment used in this study. ${ }^{16}$ The main limitation is speed of response, which was addressed by collecting the expired gas using a facemask ${ }^{17}$ rather than a headbox or incubator. Measurement of peripheral $\mathrm{Vo}_{2}$ using arterial occlusion has a coefficient of variation of $6.6 \% .{ }^{12}$ The main limitation is movement artefact at the time of occlusion, which was overcome by taking repeat measurements and having strict predetermined criteria for rejection of invalid traces.

In the resting state, global metabolic rate is highly variable and this has been observed on many previous occasions. ${ }^{18} 19$ Even a warm bath is an effective cold stress resulting in increased evaporative heat loss from the wet skin and exposure to a relatively cold environment. ${ }^{20} 21$ This leads to non-shivering thermogenesis, which uses the metabolism of brown adipose tissue to increase heat production to maintain body temperature. ${ }^{22}$ An increase in motor activity from increased movements of arms and legs during handling and crying may also have an impact.

Another mechanism for dealing with cold stress is peripheral vasoconstriction, which serves to preserve body heat. This would be expected to lead to a fall in limb temperature and a fall in skin metabolic rate. However, the impact of a rise in global metabolic rate on peripheral metabolic rate has not been previously described in the newborn. Therefore it is a most interesting finding that a rise in global metabolic rate is mirrored by a rise in peripheral $\mathrm{VO}_{2}$. Presumably muscle heat production in the limb rises to contribute to the overall increase in metabolic rate. The small fall in peripheral skin temperature after the bath suggests that major peripheral vasoconstriction had not been triggered in this study. With a more extreme degree of cold stress the results may be different.

In this study we have presented data using the same units as in our previous studies. ${ }^{12}{ }^{23}$ No assumptions on differential path length factor are required, therefore comparisons between babies are valid. Others have assumed that differential path length factor is near enough a constant to allow comparisons between babies. ${ }^{2}$ Using the same method of calculation, the mean value obtained in healthy term infants before a bath equates to $13.7 \mu \mathrm{mol} / 100 \mathrm{ml} / \mathrm{min}$. This compares well with previous studies where mean resting $\mathrm{VO}_{2}$ has been measured as 12.8 and 9.4 and $10.4 \mu \mathrm{mol} / 100 \mathrm{ml} / \mathrm{min}$ in the healthy term infant. ${ }^{12}{ }^{23}$ In normotensive sick preterm infants, the mean peripheral $\mathrm{VO}_{2}$ has been reported as $23.9 \mu \mathrm{mol} / 100$ $\mathrm{ml} / \mathrm{min}$ using a venous occlusion technique. ${ }^{2}$ Our own work comparing venous and arterial methods suggests a poor correlation, with values approximately $50 \%$ higher using the venous technique. ${ }^{12}$ Despite this difference in methodology, our results suggest that healthy term infants have lower peripheral $\mathrm{VO}_{2}$ than sick preterm infants.

The question as to whether this technique will prove to be clinically useful remains. It is very encouraging that the technique is responsive to changes that would be expected to influence peripheral $\mathrm{VO}_{2}$. In the absence of an ideal method, this is the only way to determine whether the measurements have any validity. It has already been suggested that the technique may provide useful information to determine which babies require circulatory support or transfusion. ${ }^{13}$ Should the link between global and peripheral $\mathrm{VO}_{2}$ prove to be robust, then the method could be used to determine the optimal environment for nursing sick babies. However, the interplay between temperature (core and peripheral) and $\mathrm{VO}_{2}$ measurements is likely to be of critical importance in interpretation of results. Also the responses of preterm infants to a cool environment may be significantly different ${ }^{24}$ from those of the babies we have observed. Clinical studies of sick preterm babies using the arterial occlusion technique are now required. 


\section{Conclusions}

These studies in term infants show that NIRS with arterial occlusion is a useful tool for studying peripheral $\mathrm{VO}_{2}$ in neonates. Peripheral $\mathrm{VO}_{2}$ is heavily influenced by changes in global $\mathrm{VO}_{2}$, stimulated by cold stress. This will need to be taken into consideration in the interpretation of results, if the technique is used to monitor the circulation during critical care.

\section{Authors' affiliations}

I A-A Hassan, S A Spencer, Neonatal Unit, City General Hospital, Stoke on Trent, UK

Y A Wickramasinghe, Centre for Science and Technology in Medicine, University of Keele, UK

S A Spencer, The Medical School, Keele University, UK

\section{REFERENCES}

1 Beerthuizen GI, Goris R, Kreuzer FJ. Skeletal muscle $\mathrm{PO}_{2}$ during imminent shock. Arch Emerg Med 1989;6:172-82.

2 Wardle SP, Yoxall CW Weindling AM Peripheral oxygenation in hypotensive preterm babies. Pediatr Res 1999;45:343-9.

3 Pierrat V, Duquennoy C, van Haastert IC, et al. Ultrasound diagnosis and neurodevelopmental outcome of localised and extensive cystic periventricular leucomalacia. Arch Dis Child Fetal Neonatal Ed 2001:84:F151-6.

4 Miall-Allen VM, de Vries LS, Whitelaw AG. Mean arterial blood pressure and neonatal cerebral lesions. Arch Dis Child 1987;62:1068-9.

5 Bada HS, Korones SB, Perry EH, et al. Mean arterial blood pressure changes in premature infants and those at risk for intraventricular hemorrhage. J Pediatr 1990;117:607-14.

6 Watkins AM, West CR, Cooke RW. Blood pressure and cerebral haemorrhage and ischaemia in very low birthweight infants. Early Hum Dev 1989:19:103-10.

7 Development of audit measures and guidelines for good practice in the management of neonatal respiratory distress syndrome. Report of a Joint Working Group of the British Association of Perinatal Medicine and the Research Unit of the Royal College of Physicians. Arch Dis Child 1992;67:1221-7.

8 Saliba E, Marret S. Cerebral white matter damage in the preterm infant: pathophysiology and risk factors. Semin Neonatol 2001;6:121-33.
9 Perlman JM, Risser R, Broyles RS. Bilateral cystic periventricular leukomalacia in the premature infant: associated risk factors. Pediatrics 1996;97:822-7.

10 Ambalavanan N, Carlo WA. Hypocapnia and hypercapnia in respiratory management of newborn infants. Clin Perinatol 2001;28:517-31.

11 Wiswell TE, Graziani L, Kornhauser MS, et al. Effects of hypocarbia on the development of cystic periventricular leukomalacia in premature infants treated with high-frequency jet ventilation. Pediatrics 1996;98:918-24

12 Hassan IA, Spencer SA, Wickramasinghe YA, et al. Measurement of peripheral oxygen utilisation in neonates using near infrared spectroscopy: comparison between arterial and venous occlusion methods. Early Hum Dev 2000;57:21 1-24.

13 Wardle SP, Weindling AM. Peripheral oxygenation in preterm infants. Clin Perinatol 1999;26:947-66.

14 Peters KL. Bathing premature infants: physiological and behavioral consequences. Am J Crit Care 1998;7:90-100.

15 Handley JC, Rakowski S, Spencer SA. An investigation to determine whether the thermoneutral state can be predicted from measurements of peripheral or differential skin temperature. Early Hum Dev 1991;26:230.

16 Handley JC, Spencer SA, Rakowski S, et al. Critical appraisal and further development of the methodology for open circuit calorimetry in neonates. Early Hum Dev 1991;26:167-76.

17 Smales OR. Simple method for measuring oxygen consumption in babies. Arch Dis Child 1978;53:53-7.

18 Hey EN, O'Connell B. Oxygen consumption and heat balance in the cot-nursed baby. Arch Dis Child 1970;45:335-43.

19 Rutter N, Brown SM, Hull D. Variations in the resting oxygen consumption of small babies. Arch Dis Child 1978:53:850-4

20 Johanson RB, Richardson S, Spencer SA, et al. Relative changes in neonatal body temperature: after birth and after a bath. Early Hum Dev 1991;26:230-1.

21 Sjors G, Hammarlund K, Kiartansson S, et al. Respiratory water loss and oxygen consumption in full-term infants exposed to cold air on the first day after birth. Acta Paediatr 1994;83:802-7.

22 Hull D. Nutrition and temperature control in the newborn baby. Proc Nutr Soc 1969:28:56-61.

23 Hassan IA, Wickramasinghe YA, Spencer SA. Effect of limb cooling on peripheral and global oxygen consumption in neonates. Arch Dis Child Fetal Neonatal Ed 2003;88:139-42.

24 Wheldon AE, Hull D. Incubation of very immature infants. Arch Dis Child 1983;58:504-8. 